\title{
SUPERCRITICAL WATER LOOP DESIGN FOR CORROSION AND WATER CHEMISTRY TESTS UNDER IRRADIATION
}

\author{
MARIANA RŮŽIČKOVÁ, PETR HÁJEK, ŠTEPAN ŠMIDA', RUDOLF VŠOLÁK, JAN PETR² and JAN KYSELA \\ Nuclear Research Institute Rez plc, Reactor Services Division, 25068 Husinec - Řez 130, Czech Republic \\ ${ }^{1}$ H\&D Engineering, Michelská 792/2, 14000 Praha 4, Czech Republic \\ ${ }^{2}$ Nuclear Research Institute Rez plc, Energoprojekt Division, Vyskocilova 3/741, 14000 Praha 4, Czech Republic \\ ${ }^{*}$ Corresponding author. E-mail : ruz@ujv.cz
}

Received June 15, 2007

Accepted for Publication November 15, 2007

An experimental loop operating with water at supercritical conditions $\left(25 \mathrm{MPa}, 600^{\circ} \mathrm{C}\right.$ in the test section) is designed for operation in the research reactor LVR-15 in UJV Rez, Czech Republic. The loop should serve as an experimental facility for corrosion tests of materials for in-core as well as out-of-core structures, for testing and optimization of suitable water chemistry for a future HPLWR and for studies of radiolysis of water at supercritical conditions, which remains the domain where very few experimental data are available. At present, final necessary calculations (thermalhydraulic, neutronic, strength) are being performed on the irradiation channel, which is the most challenging part of the loop. The concept of the primary and auxiliary circuits has been completed. The design of the loop shall be finished in the course of the year 2007 to start the construction, out-of-pile testing to verify proper functioning of all systems and as such to be ready for in-pile tests by the end of the HPLWR Phase 2 European project by the end of 2009.

KEYWORDS : Supercritical Water, Reactor Loop, Materials Testing, Water Chemistry, Radiolysis

\section{INTRODUCTION}

Activities in the Nuclear Research Institute in Rez, Czech Republic, on the Supercritical Water Loop (SCWloop) are part of a European joint research project, called High Performance Light Water Reactor Phase 2 (HPLWR Phase 2), co-funded by the European Commission [1]. Its construction and out-of-pile tests to assess its proper performance will be conducted during this project.

The SCW-loop is designed for operation inside research reactor LVR-15 in the Nuclear Research Institute Rez, plc to be used as an experimental facility mainly for corrosion studies of materials, studies of radiolysis in supercritical water and water chemistry optimization. The temperature and pressure in the testing zone of the irradiation channel are $600^{\circ} \mathrm{C}$ and $25 \mathrm{MPa}$. The loop shall enable expansion of existing knowledge mainly on material performance from un-irradiated to irradiated conditions and radiolysis modeling from sub-critical to supercritical conditions.

The research reactor LVR-15 is a tank type reactor with the following characteristics: nominal power $10 \mathrm{MW}$, fuel: IRT-2M (enrichment $36 \%$ ), thermal flux: $1.5 \times 10^{18} \mathrm{n} / \mathrm{m}^{2} \mathrm{~s}$ and fast flux: $2.5 \times 10^{18} \mathrm{n} / \mathrm{m}^{2} \mathrm{~s}$.

The following article gives overview of the recent activities in loop design, especially in design of the irradiation channel, as well as a summary of possible purposes and experiments to be performed in the future inside the loop, where some details must still be clarified and remaining open questions resolved. The open questions relate especially to internal instrumentation, e.g. for possible electrochemical measurements, measurements for studies of radiolysis of water at supercritical conditions etc.

\section{IRRADIATION CHANNEL: INITIAL SPECIFICATION FOR DESIGN}

The location of the irradiation channel in the grid of the reactor core imposes the following geometrical and constructional constraints on the channel:

i. Maximum external diameter of the pressure tube is given by its position in aluminium "spacer" in a single cell of the core; consequently, the maximum external diameter is $57 \mathrm{~mm}$ and the maximum internal diameter for given working parameters of the medium is $37 \mathrm{~mm}$.

ii. Maximum temperature of the pressure tube wall is $450^{\circ} \mathrm{C}$ due to structural materials for loop construction ( $\mathrm{Ti}$ stabilized $18 \mathrm{Cr} 10 \mathrm{Ni}$ stainless steel) having certification 
for use in a nuclear facility only up to this temperature. iii. length of the irradiation channel is about $5000 \mathrm{~mm}$.

iv. Temperature and pressure in the area for sample location are $600^{\circ} \mathrm{C}$ and $25 \mathrm{MPa}$ respectively.

$v$. The irradiation channel design must enable proper operation of the loop both with and without $\gamma$-heating generated by the reactor.

vi. Maximum power of the electrical heating is limited to $\sim 15 \mathrm{~kW}$ due to space restrictions.

vii. Maximum pressure drop is $\sim 0.3 \mathrm{MPa}$ (imposed by the characteristics of the main circulating pump).

\section{IRRADIATION CHANNEL DESCRIPTION}

The irradiation channel is composed of a pressure tube embedded in aluminium "spacer" (Fig. 1), which serves as isolation element between the pressure tube at $\sim 450^{\circ} \mathrm{C}$ and reactor water at $\sim 50^{\circ} \mathrm{C}$. The space between the pressure tube and the spacer is filled with air.

The channel internals are formed by several coaxial tubes, which provide the required flow, regeneration exchanger, electrical heating, isolation elements and numerous fixing and stabilizing elements. The desired high temperature inside the sample area is reached by a regeneration exchanger placed above the sample area. Due to the high temperature difference between both water inlet and outlet (both $\sim 450^{\circ} \mathrm{C}$ ) on one hand and the sample

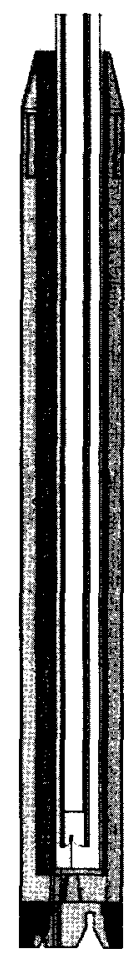

Fig. 1. Pressure Tube (Green) and Aluminium Spacer (Blue) area $\left(600^{\circ} \mathrm{C}\right)$ on the other hand, the regeneration exchanger occupies most of the space inside the irradiation channel. To achieve a reasonable temperature at the inlet and outlet of the irradiation channel, the regeneration exchanger performs both cooling and heating functions. The inlet water serves as a cooling agent for the external pressure tube to maintain the temperature at $450^{\circ} \mathrm{C}$ maximum. The regeneration exchanger together with complementary electrical heating and eventually $\boldsymbol{\gamma}$-heating while the reactor is in operation serves to achieve the desired temperature inside the sample area, i.e. $600^{\circ} \mathrm{C}$. The $\gamma$-heating of the LVR-15 reactor is $\sim 3 \mathrm{~W} / \mathrm{g}$, i.e. $\sim 17 \mathrm{~kW}$ for this loop. After leaving the sample area, the regeneration exchanger re-cools the water to an acceptable temperature before it exits the channel.

At the time of publication of this paper, there exists 2 principle design concepts of the arrangement of internals inside the pressure tube of the irradiation channel (Fig. 2); the concepts differ from each other in the means used for reducing heat losses during internal flow of water through the irradiation channel. The decision between the 2 concepts will be made based on thermalhydraulic analysis of both concepts. The concept from Fig. $2 b$ seems more feasible but detailed calculations still have to be performed. The regeneration exchanger is made of 36-37 stainless steel tubes $3 \times 0.2 \mathrm{~mm}$; six of the tubes are occupied by wiring of the electrical heating, which come out at the top of the channel. The tubes of the regeneration exchanger are either close packed inside a hexagon (Fig. 2a) or arranged in the same hexagon around a central tube (Fig. 2b), which serves as the first upcoming path of water. The regeneration exchanger is fixed with barriers arranged in a descending helix that play the role of stabilizing elements and, at the same time, orient the flow spirally on the secondary side of the heat exchanger (Fig. 3).

As mentioned above, the electrical heating and eventually the $\gamma$-heating provided by the reactor are the additional heat sources inside the irradiation channel. The available

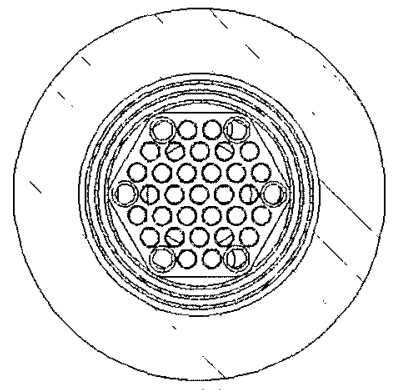

(a)

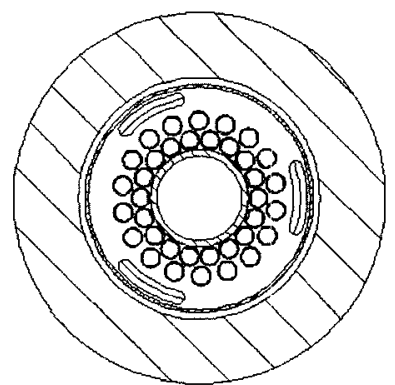

(b)
Fig. 2. Cross-Section of the Irradiation Channel in the Location of the Regeneration Exchanger. (a) Concept of the Heat Exchanger with Close-Packed Tubes and (b) With Tubes Arranged Around a Central Tube 


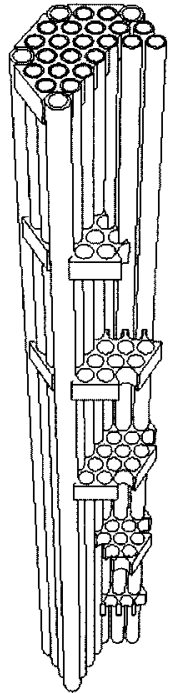

Fig. 3. Barriers Arranged Into Descending Helix for Orienting Flow on the Secondary Side of the Heat Exchanger

inter-tubular space in the channel limits the power of the electrical heating to a maximum of $\sim 15 \mathrm{~kW}$. While the reactor is in operation, the $\gamma$-heating is used to overcome the pseudo-critical point, i.e. water enters the channel at a temperature below the pseudo-critical temperature and heats up above it in the lower part of the irradiation channel situated in the reactor core. In case the reactor is not in operation, water is heated above the pseudo-critical point before entering the irradiation channel. In both cases, water has the same parameters at the core outlet.

Due to the amount of heat transferred from the heat exchanger to the external pressure tube, the thermalhydraulic analyses have brought forth the necessity for isolation at the external surface of the heat exchanger and around the electrical heating. The isolation is realized by spaces filled with stagnant water. The isolation of the heat exchanger required use of different tube material and thinning of their walls. The complicated thermal field has also resulted in the need of cross-flow at outlet from the sample area, which requires a rather precise manufacturing of a cross-flow element (Fig. 4). In general terms, the complicated thermal field has led to a technologically very complicated design of the irradiation channel, which sets very high demands especially on the manufacturing process.

\section{INSTRUMENTATION}

The purpose of the SCW-loop is primarily to be an experimental facility for corrosion testing of materials for the reactor cooled by supercritical water, the High Performance Light Water Reactor (HPLWR), for studies on water radiolysis at supercritical conditions and testing the envisaged water chemistries to be applied during future operation of real plants. These objectives require suitable instrumentation for obtaining the relevant operational data and results. The choice of instrumentation is somewhat limited compared to non-active facilities with similar objective owing especially to technological, irradiation, space and safety demands of the experimental reactor LVR-15.

For the presented design, samples of tested materials in the form of coupons are envisaged. They will be fixed by screws on a support; the support and the samples will be isolated from each other to avoid galvanic coupling (Fig. 5). A suitable reference electrode to measure electrochemical (ECP) and redox potentials of the samples is also being considered, even though difficulties are expected due to the lack of a suitable sensor which could

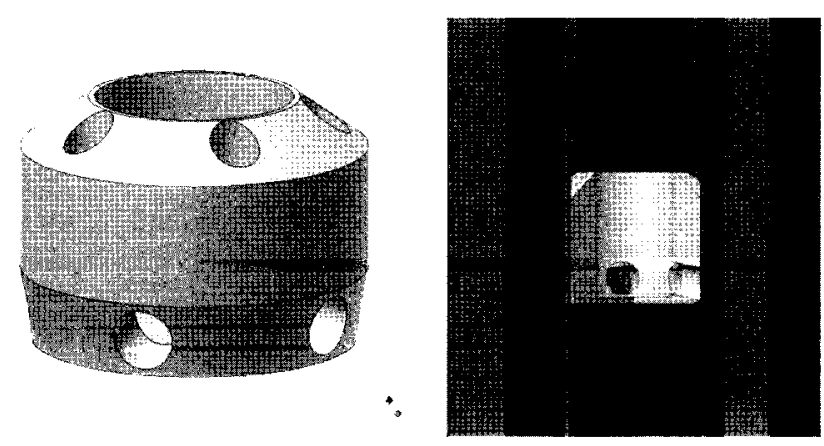

Fig. 4. The Cross-Flow Element Individually (Left) and in Its Location in the Channel - the Cross Flow Element is Yellow (Right)

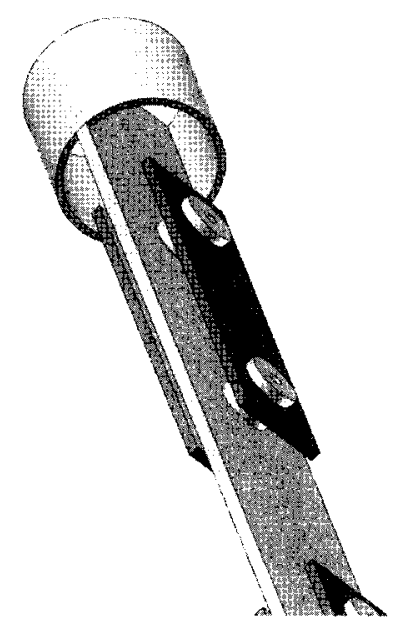

Fig. 5. Sample Holder for Material Coupons 
withstand radiation and the high temperatures and pressures. If a suitable sensor is available, electrical connection of the samples is assumed by hard-line wires passing through the tubes of the regeneration exchanger. Two reference electrodes are presently planned to be placed at the inlet and outlet of the irradiation channel; nevertheless, this causes difficulties with measuring ECP for two reasons: the temperature is much lower than in the sample area $\left(\max .450^{\circ} \mathrm{C}\right.$ as stated above) and the sensor would be installed on the tubing, which serves as sample (= working electrode). In this case, only the redox potential measurement is of meaning because it can to some extent trace changes in the oxidation power of the coolant.

For tests of materials performance under applied stress, irradiation channel internals will have to be adapted for sample loading; this option is not being elaborated yet. In UJV, there is experience with hydraulic loading of relatively large CT samples for tests of stress corrosion cracking (SCC) in a BWR-simulating loop [2].

\section{AUXILIARY CIRCUITS}

The SCW-loop is a closed loop with forced circulation of the coolant through irradiation channel; a simplified layout of auxiliary circuits is shown on (Fig. 6). The loop is composed of circuits and systems as follows:

- Primary circuit maintains the required experimental parameters. The key components are:

- Irradiation channel, as described above;

- Heat exchanger for regeneration of heat from coolant outlet to coolant inlet into irradiation channel. This regeneration exchanger is an optional apparatus, which may not be necessary in case the main circulating pump manages operation at relatively high temperatures;

- Cooler for heat removal from primary into secondary circuit and for regulation of primary coolant temperature at inlet into the main circulating pump;

- Main circulating pump ensures adequate pressure drop for the primary circuit as well as the purification system;
(T)

(T)

(T)

(T)

(T)

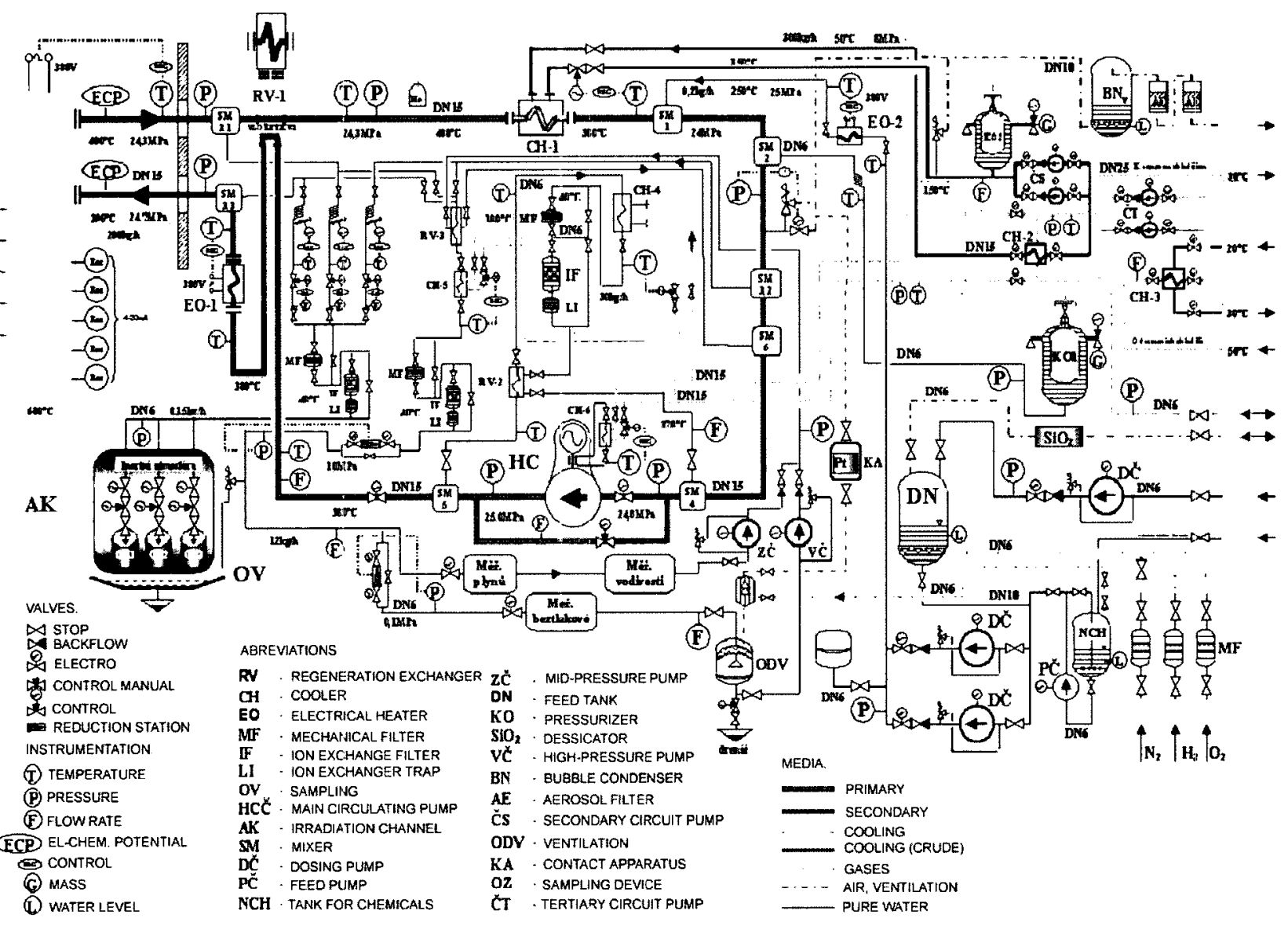

Fig. 6. Technological Layout of the Auxiliary Circuits of the SCW-Loop 
- Electrical heater for heating the coolant before entering the irradiation channel. The electrical heater must have sufficient power reserve for outof-pile testing of the loop as well as for proper loop operation when the reactor is shut-down (when heat provided by $\gamma$-radiation of the reactor is lacking);

- Pressurizer;

- Sampling and mixing components.

- System for purification of primary coolant: primary water is cooled before filtration by a regeneration exchanger and a cooler and re-heated before entering the primary circuit.

- System for measurement of primary coolant: primary water is depressurized for necessary on-line measurements. After measurement, water is re-heated by a regeneration exchanger and a cooler and returned to the primary circuit.

- Sampling system, where samples are accumulated in a reservoir for periodic sampling.

- System for preparation and feeding of medium, which enables dosing of gases into the feedwater.

- Organized outflow for quantity control and drainage.

- Secondary and tertiary circuit.

- Control system.

- Power supply system.

- UPS system.

\section{WATER CHEMISTRY AND RADIOLYSIS}

Water chemistry specifications for materials testing in supercritical water come from the present practice in water chemistry control in conventional light water reactors (LWR), especially the boiling water reactors (BWR), where normal water chemistry (NWC) and hydrogen water chemistry (HWC) are the candidates. Normal water chemistry, initially defined as pure water, contains certain amounts of oxygen at the outlet produced by radiolysis of water in the core. In non-active experimental facilities such as autoclaves, it can be simulated by additions of oxygen. Under the hydrogen water chemistry, dosing of hydrogen into the feedwater is applied in order to scavenge oxygen produced by radiolysis. For the purpose of simulating the defined water chemistry during the tests inside the SCW-loop, the loop is equipped with systems for dosing and measurement of gases.

The radiolysis of water at supercritical conditions is a factor that will influence real water chemistry parameters; however, sufficient experimental data are still missing. Data on kinetics of radiolytic reactions and chemical yields (G-values) of decomposition products can be obtained from pulse radiolysis experiments; these data can be used for creating a radiolysis model for the actual experimental facility. For radiolysis studies in the SCWloop, both kinds of data will be needed: pulse radiolysis data for the radiolytic model and experimental data from the loop to verify the model. For proper verification of the model, appropriate sampling locations and lines must be chosen along the loop for chemical measurements, especially for hydrogen peroxide $\mathrm{H}_{2} \mathrm{O}_{2}$, which decomposes rapidly on the walls of steel pipes. UJV already has experience with radiolysis studies, measurements and modelling in a BWR-simulating loop [3], which can be used as the basis for extending the knowledge on water radiolysis from sub- to supercritical conditions.

\section{FUTURE TASKS}

Once the design of the irradiation channel and the auxiliary circuits is completed, parts that will be exposed to irradiation (irradiation channel and safety valves) will be submitted to licensing by the State Office for Nuclear Safety. Considering that the loop is designed for physical parameters higher than any existing nuclear facility, several challenges with licensing the irradiation channel are expected, especially in reaching the required material limits in terms of mechanical properties with respect to temperature, strength properties, oxidation resistance of constructional materials and other.

Additional difficulties are expected with providing specific channel components of unusual sizes from commercial manufacturers, in particular those that will be subjected to the highest temperatures, which must be manufactured from nickel-based alloys. Search for solution of several other open tasks, such as the installation of redox and/or reference sensors into the irradiation channel, will be proceeding after the design is completed.

\section{CONCLUSION}

Design activities on the Supercritical Water Loop aim at construction of an experimental facility for corrosion, radiolysis and water chemistry studies in water at supercritical conditions. The SCW-loop will be operated in the research reactor LVR-15 in UJV Rez. Most of the present effort is targeted on the design of the irradiation channel, which is the part of the loop located inside the research reactor. The rather complicated design of the irradiation channel results from the many technological, safety and spatial constraints imposed by the reactor itself as well as from the status of the loop as nuclear facility.

\section{ACKNOWLEDGEMENT}

The authors wish to thank the partners of the HPLWR Phase 2 project and the European Commission for financial support of the project, contract $\mathrm{n}^{\circ} 036230$.

\section{REFERENCES}

[1] T. Schulenberg, J. Starflinger: "European research project on high performance light water reactors," Proc. $3^{\text {rd }}$ Int. Symp. on SCWR - Design and Technology, March 12-15, 
2007, Shanghai, China, Paper No. SCR2007-I001.

[ 2 ] Hoffmann, H., Hüttner, F., Ilg, U., Wachter, O., Widera, M., Bro zová, A., Ernestová, M., Kysela, J., V`solák, R. "Crack growth tests on a ferritic reactor pressure vessel steel under the simultaneous influence of simulated BWR coolant and irradiation," VGB PowerTech, 2004, 84, No.
9, 76-80.

[3 ] J. Kysela, M. Ernestová, V. Linek, J. Moucha, W. Ruehle, "Corrosion potential dependence on oxygen, hydrogen and hydrogen peroxide in reactor water loop at BWR conditions", Water chemistry of nuclear systems 8 , Bournemouth, UK, 22-26 October 2000. 